\title{
JUURNAL_RU
}

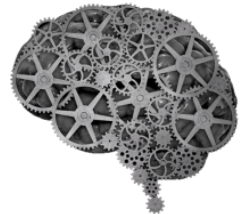

COMPANY GROUP "INTELLEKT"

Бондарь С.C. Тульский государственный университет Тула, Россия

doi: 10.18411/1j2016-3-08

\section{Мониторинг функционального состояния внутренних органов у пациентов с пневмонией методом активной радиометрии}

Отечественные разработки в сфере микроэлектроники, осуществлявшиеся в период с 50-х годов прошлого столетия, приведшие к развитию радиолокационных технологий, в результате процессов конверсии и диверсификации дали начало новой медицинской технологии - активной радиометрии в СВЧ-диапазоне (AР) $[1,2]$. Активная радиометрия позволяет регистрировать слабое радиоизлучение тканей организма, с построением топографических карт его распределения по поверхности области исследования. При этом регистрируемое радиоизлучение отражает метаболическую активность тканей, изменяясь пропорционально выделению молекул воды при протекании биохимических процессов в клетках $[1,3]$.

Цель исследования - доказать возможность выявления патологических изменений органов грудной полости методом активной радиометрии.

Материалы и методы исследования. На клинической базе кафедры терапии Саратовского военно-медицинского института в период с 2004 по 2010 г. проведено проспективное контролируемое исследование диагностических возможностей метода АР в ходе которого обследовано 200 пациентов, из них 120 пациентов мужского пола в возрасте 18-20 лет с внебольничной бактериальной пневмонией (ВП) и 80 практически здоровых лиц мужского пола. 
Активная радиометрия проводилась с использованием диагностического комплекса «Аквафон» (регистрационное удостоверение ФСР 2010/07292) [4-7].

Оценка интенсивности излучения внутренней среды организма проводилась с использованием средних значений величины радиосигнала по сторонам грудной клетки (радиоотклик среды - PO, а так же с использованием суммарного значения амплитуды резонансного радиоотклика со всех точек регистрации - (волновая активность среды - ВА) [4, 9].

Анализ результатов проведенного исследования проводился с помощью программы Statistica 6.0 (Stat Soft, США).

Результаты исследования. Результаты исследования представлены в табл.1.

Таблица

Значения волновых показателей в группах наблюдения (ед.)

\begin{tabular}{|c|c|c|c|c|c|c|}
\hline \multirow{2}{*}{ Показатель } & \multicolumn{5}{|c|}{ Группы } \\
\cline { 2 - 7 } & $x$ & $\begin{array}{c}-95 \% \\
\text { ДИнтроль }\end{array}$ & $\begin{array}{c}+95 \% \\
\text { ДИ }\end{array}$ & $x$ & $\begin{array}{c}-95 \% \\
\text { ДИ }\end{array}$ & $\begin{array}{c}+95 \% \\
\text { ДИ }\end{array}$ \\
\cline { 2 - 7 } & & 96,2 & 100,1 & 120,6 & 117,4 & 123,9 \\
\hline РО (слева) & 98,1 & 95,2 & 97,9 & 115,5 & 112,8 & 118,1 \\
\hline РО (справа) & 96,6 & 4123,1 & 4324,6 & 5014,1 & 4891,3 & 5437,5 \\
\hline ВА & 4223,3 & 412 & & & \\
\hline
\end{tabular}

Проведенный анализ свидетельствует о статистически значимых различиях ( $\mathrm{p}=0,001)$ уровня ВА у практически здоровых лиц и пациентов с ВП, что позволяет использовать данный показатель с целью мониторинга патологических изменений у пациентов ВП и контроля процесса лечения.

На рисунке представлена динамика РО, числа лейкоцитов периферической крови (L), СОЭ, температуры тела (t) у пациентов с ВПТТ, Значения анализируемых показателей приведены в условных единицах. 


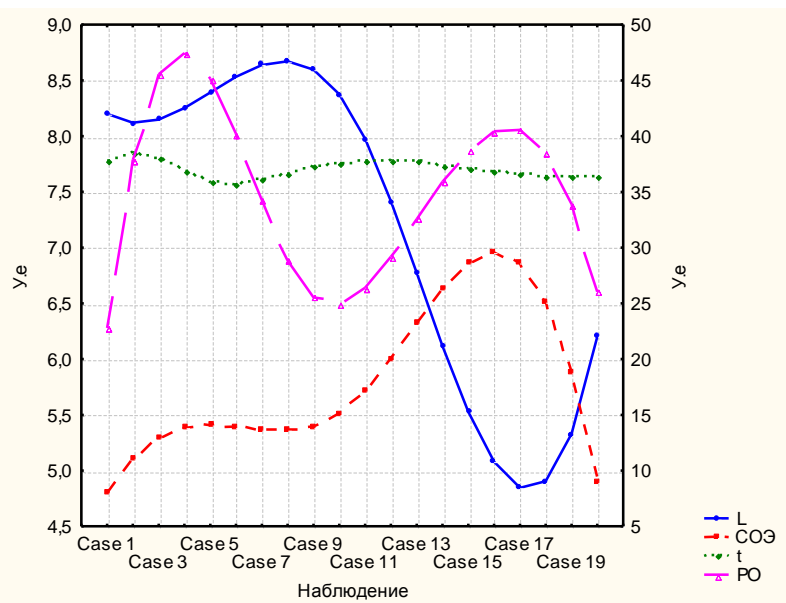

Рис. Динамика лабораторных показателей и ВА

Результаты исследования указывают на фазово-зависимый характер имеющихся связей лабораторных показателей и ВА.

\section{Заключение.}

Учитывая, что ВА является чувствительным методом диагностики состояния транскапиллярного обмена, а сам ТКО модулируется нейроэндокринными влияниями, очевидно, что изменение радиометрических показателей у таких больных отражает функциональное состояние организма [11-14]. Таким образом, АР может использоваться для диагностики патологических изменений внутренних органов в клинической практике. 


\section{Литература:}

1. Избранные технологии диагностики: Монография / В.М. Еськов и др.; под ред. А.А. Хадарцева, В.Г. Зилова, Н.А. Фудина. Тула: ООО РИФ «ИНФРА», 2008. $296 \mathrm{c}$.

2. Терехов И.В. Транс-резонансная функциональная топография в диагностике заболеваний органов дыхания (новый метод обработки информации): автореф. дисс. канд. мед. наук. Тула, 2007. 24 с.

3. Применение метода ТРФ-топографии в диагностике воспалительных изменений нижних отделов респираторного тракта / Терехов И.В., Громов М.С., Парфенюк В.К. и др. // Саратовский научно-медицинский журнал. 2008. T. 4. № 1. C. 79-83.

4. Возможность использования активной СВЧ-радиометрии для оценки альвеолярно-капиллярной проницаемости в эксперименте / Терехов И.В., Солодухин К.А., Аржников В.В. и др. // Регионарное кровообращение и микроциркуляция. 2011. Т. 10. № 4. С. 83-86.

5. Терехов И.В., Дзюба М.А., Наджарьян Л.С. Оценка альвеолярнокапиллярных нарушений при развитии тяжелого гемодинамического отека легких у крыс и их коррекция с помощью СВЧ-излучения // Саратовский научно-медицинский журнал. 2011. Т. 7. № 2. С. 389-392.

6. Применение транс-резонансной функциональной топографии с целью оптимизации диагностической тактики у пациентов с подозрением на острый панкреатит и его осложнения / Лобаков А.И., Громов М.С., Дубовицкий С.А., Тер-Симонян Г.В., Терехов И.В. и др. // Хирург. 2008. № 8. С. 22-33.

7. Трансрезонансная функциональная топография в оптимизации диагностики у пациентов с подозрением на острую воспалительную патологию органов брюшной полости / Громов М.С., Масляков В.В., Брызгунов А.В., Терехов И.В. и др. // Анналы хирургии. 2008. № 6. С. 60-63.

8. Идентификация и дифференциация костных новообразований методом активной радиометрии / Незнамов М.Н., Зайцев В.А., Ругина Н.А., Бондарь 
С.С., Терехов И.В. // Вестник новых медицинских технологий. Электронное издание. 2015. Т. 9. № 2. С. 20.

9. Использование радиоволнового зондирования водосодержащих сред миокарда у больных с артериальной гипертензией / Терехов И.В., Солодухин К.А., Никифоров В.С., Ломоносов А.В. // Российский кардиологический журнал. 2013. № 5 (103). С. 40-43.

10. Терехов И.В., Логаткина А.В., Бондарь С.С. Функциональное состояние миокарда и его связь с состоянием водосодержащих сред органов грудной клетки при инфильтративных процессах в легких // Stredoevropsky Vestnik pro Vedu a Vyzkum. 2015. T. 51. C. 3.

11. Терехов И.В., Парфенюк В.К. Мониторинг инфильтративных процессов нижних отделов респираторного тракта у пациентов с внебольничной пневмонией методом люминесцентного анализа в радиодиапазоне // Вестник восстановительной медицины. 2009. № 3. С. 46-50.

12. Интегральная оценка воспалительного процесса у больных внебольничной пневмонией методом активной радиометрии / В.В. Аржников, В.Б. Лифшиц, В.К. Парфенюк, И.В. Терехов // Саратовский научно-медицинский журнал. 2011. T. 7. № 4. C. 817-822.

13. Громов М.С., Терехов И.В. Характеристика системного воспалительного ответа у больных внебольничной пневмонией в динамике при помощи активной СВЧ-радиометрии // Казанский медицинский журнал. 2010. Т. 91. № 5. С. 611-614.

14. Громов М.С., Аржников В.В., Терехов И.В. Возможности оценки функционального состояния организма с помощью собственного радиоизлучения нетепловой природы // Медицинский вестник МВД. 2008. № 5 (36). C. 38-43.

15. Дифференциальная диагностика заболеваний грудной клетки с помощью транс-резонансной функциональной топографии / Терехов И.В., Петросян 
В.И., Громов М.С., Масляков В.В. и др. // Вестник медицинского института "РЕАВИЗ": реабилитация, врач и здоровье. 2013. № 3 (11). С. 18-26.

16. Диагностика и мониторинг инфильтративных процессов в грудной полости с помощью люминесцентного излучения водосодержащих сред / Аржников В.В., Терехов И.В., Громов М.С. // Медицинский вестник МВД. 2009. № 2 (39). C. 40-46.

17. Терехов И.В. Оценка сосудистой проницаемости с помощью активной радиометрии // Аспирантский вестник Поволжья. 2009. № 7-8. С. 187-190.

18. Технология динамической оценки воспалительного процесса с помощью активной резонансной радиометрии / Терехов И.В., Громов М.С., Петросян В.И., Бондарь С.С. и др. // Вестник новых медицинских технологий. 2010. Т. 17. № 1. C. 135-137.

19. Дифференциация инфильтративных изменений в легких с помощью топографического картирования СВЧ-излучения органов грудной полости / Громов М.С., Терехов И.В., Бондарь С.С., Дзюба М.А., Аржников В.В. // Вестник новых медицинских технологий. 2010. Т. 17. № 3. С. 208-211. 